\title{
Gaining a patient's perspective while becoming a doctor
}

\section{A medical student learns by seeing the system from the other side}

\footnotetext{
wo doctors, both aged over 70 years, teach our rotation of medical students. They stress "old-fashioned"

values, including accurate history-taking, thorough physical examination, punctuality and courtesy. In an era of high-technology medicine and high patient throughput, how relevant are these dated principles?

Assigned to the best private hospital in the city, crammed
} with top specialists for my clinical placement year, it was downhill from there, I believed. I headed off to play squash after observing a protracted total hip replacement one night and felt on top of my game. A tinge of arrogant invincibility may have been the incentive to stretch just a bit further for an impossibly low wall shot. I reached it, won the point and tore my plantaris, soleus and gastrocnemius muscles at the same time.

Rest, ice, compress, elevate; just one of countless mnemonics to implement. I attended our surgery rotation on borrowed crutches the next morning and sought an informal opinion. With the coffee table between us, the consultant proclaimed: "gastroc's largely intact and will heal with immobilisation - no need for surgery - you'll be fine". In naive faith, I hobbled between operating theatres in a loaned orthopaedic boot. Pain is for wimps, doctors don't take time off and the course very effectively weeds out those who cannot cope. By the end of the week I realised I was a wimp. My leg started to swell and I could no longer sleep so I sheepishly took myself to the hospital's accident and emergency centre.

I was grateful to be bulk-billed and seen after a long list of the more deserving, who had paid to be there. Had I not been the patient in this scenario, I might have breezed in to solicit a clinical history and been irritated by a patient's rambling version of events when all I needed was a concise and structured account for my case presentation. I prepared for the interrogation, determined I would impress. Finally, the big moment arrived. There were no students, only the specialist and he was clearly rushed. I felt like a freeloader. He asked how I had injured my calf, cut me off to write a request for ultrasound and vanished. After being parked in the corridor for a couple of hours, I was wheeled to ultrasound with a referral letter that stated annoyingly, "the patient showed no obvious signs of discomfort", and made a host of other statements, some accurate, that must have been transferred from me by telepathy. The ultrasound technician was equally terse. Seeing my trousers still on, she reiterated they were "very busy". I was wheeled back to accident and emergency for another hour until the specialist popped his head around the corner and said, "deep vein thrombosis", and, while reading the ultrasound report, asked the nurse to give me a shot of low molecular weight heparin (you don't need consent from a medical student). Once done, he came back with a prescription and

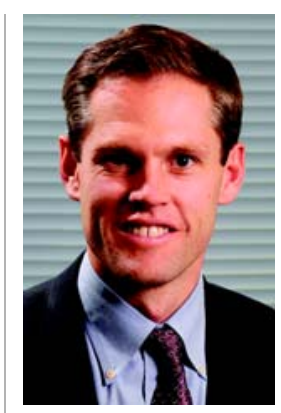

Lloyd Reeve-Johnson DVM\&S, PhD, Medical Student

Griffith University, Brisbane, QLD.

lloyd@goydpark.com

doi: 10.5694/mjal2.11666

I was wheeled to ultrasound with a referral letter that made a host of statements, some accurate, that must have been transferred from me by telepathy instructed me to self-inject twice daily, purchase graduated compression stockings and make an appointment with a vascular physician. As he attempted an exit I asked about pain control and was told to continue over-the-counter preparations. I hobbled off for 2 hours of painful waiting to get the prescription, and another half hour to work out that the stockings they measured me for (twice) were not in stock. My wife drove me around the city in search of another source; a faxed prescription then had to be sought while we waited out the remaining hours of the day. No time for ice, compression or elevation!

Three days later, still in agony, unable to sleep or study, I managed with difficulty to convince the vascular specialist's receptionist to squeeze me in between appointments 5 days early. This time there was no reduction in fees and I began to worry whether I could afford it. No examination was performed and no history taken. My request for an opiate was granted and I learned that the deep vein thrombosis was over $70 \mathrm{~cm}$ long and would be imaged again in a couple of months. The big fee however came with new advice: "mobilise ... and get back to hospital if you cough blood". I hobbled down another long corridor to the pathology lab and waited another hour for a blood test. My calf throbbed and I received a stern look from the receptionist when I attempted to elevate it onto the chair opposite. I contemplated whether one specialist's advice to immobilise had now been trumped by new advice to mobilise. At least the opiate allowed me to sleep. I tried to study but achieved little except worrying about my medical bill and inability to continue my part-time job, not to mention that our university is inflexible - miss 2 weeks and you fail the year. So, not daring to incur the wrath of surgeons by sitting down, I dutifully perched around the surgery table for the rest of the month.

After rounds, one of the elderly doctors nominated me to present a case. I had not had the energy to get around the wards and had contemplated abandoning the course when reimaging showed a near total rupture of the Achilles tendon that had been missed. We "de-identify" patients, so I presented my own case to cover for my failure to find a suitable case to present. He took me aside and told me that, in his opinion, it was a priority that I miss his tutorials for the rest of the week and sit with my leg up. By the following Monday, the swelling that had refused to diminish over weeks had receded. I was able to stop taking opiates and start to study again. My iconic, highpressure, state-of-the-art mentors, thriving on challenging cases and for whom every minute is valuable had failed, over many weeks, to notice a person behind the condition.

The most valuable lesson I learned at the best private hospital in town is what it is like to be a patient.

Acknowledgements: I thank Jon Douglas for his mentorship.

Competing interests: No relevant disclosures. 